\title{
Development and application of fluorescent SDF-1 derivatives.
}

\section{$\operatorname{AUTHOR}(S)$ :}

Masuda, Ryo; Oishi, Shinya; Tanahara, Noriko; Ohno, Hiroaki; Hirasawa, Akira; Tsujimoto, Gozoh; Kodama, Eiichi; Matsuoka, Masao; Fujii, Nobutaka

\section{CITATION:}

Masuda, Ryo ...[et al]. Development and application of fluorescent SDF1 derivatives.. Future medicinal chemistry 2012, 4(7): 837-844

\section{ISSUE DATE:}

2012-05

URL:

http://hdl.handle.net/2433/174342

\section{RIGHT:}

(c) 2012 Future Science Ltd.; この論文は出版社版でありません。引用の 際には出版社版をご確認ご利用ください。; This is not the published version. Please cite only the published version. 


\section{Development and Application of Fluorescent SDF-1 Derivatives}

Ryo Masuda, ${ }^{\dagger}$ Shinya Oishi, ${ }^{\dagger} *$ Noriko Tanahara, ${ }^{\dagger}$ Hiroaki Ohno, ${ }^{\dagger}$ Akira Hirasawa, ${ }^{\dagger}$ Gozoh Tsujimoto, ${ }^{\dagger}$ Eiichi Kodama ${ }^{\ddagger}, \S$ Masao Matsuoka ${ }^{\ddagger}$ and Nobutaka Fujii ${ }^{\dagger} * *$

${ }^{\dagger}$ Graduate School of Pharmaceutical Sciences, Kyoto University, Sakyo-ku, Kyoto 606-8501, Japan;

${ }^{\ddagger}$ Institute for Virus Research, Kyoto University, Sakyo-ku, Kyoto 606-8507, Japan

*Corresponding authors.

Graduate School of Pharmaceutical Sciences, Kyoto University, Sakyo-ku, Kyoto 606-8501, Japan Tel: +81-75-753-4551; Fax: +81-75-753-4570

E-mail: soishi@pharm.kyoto-u.ac.jp (S.O.); nfujii@pharm.kyoto-u.ac.jp (N.F.)

${ }^{\S}$ Present address: Division of Emerging Infectious Diseases, Tohoku University School of Medicine, 2-1 Seiryocho, Aoba-ku, Sendai 980-8575, Japan. 


\begin{abstract}
Background: SDF-1/CXCR4 signaling plays key roles in directed cell migration under physiological and pathological conditions. To develop agonist-based CXCR4 probes for detection of CXCR4 expression on cell lines and metastatic tumors, structure-activity relationship analyses of fluorescent SDF-1 derivatives were carried out. Results: Several SDF-1 derivatives with a single fluorescent label were designed and synthesized. Modification of the SDF-1 C-terminus with AlexaFluor ${ }^{\circledR} 488$ or tetramethylrhodamine provided potent CXCR4 probes. Using a potent probe, a novel binding inhibition assay was established for biological evaluation of potential CXCR4 ligands. Conclusions: SDF-1 derivatives with C-terminal modification exhibit equipotent binding with CXCR4 and an alternative SDF-1 receptor CXCR7 to unlabeled SDF-1. The SDF-1 derivatives are applicable to flow cytometry to detect the receptor expression and identify binding compounds for CXCR4.
\end{abstract}

\title{
Key terms
}

Chemokine: Chemotactic cytokines to regulate a number of biological processes including leukocyte trafficking, hematopoiesis and angiogenesis by the interaction with G-protein-coupled receptors.

Receptor Internalization: Translocation of cell surface receptors into intracellular compartment to induce desensitization and degradation of the receptors.

Polyphemusin II: An anti-microbial peptide isolated from the hemocytes of a horseshoe crab Limulus polyphemus.

Bicyclam: Molecules that contain two macrocyclic nitrogen heterocycles to form metal chelate complexes.

Click chemistry: Facile and simple reactions to efficiently produce the target substances under mild conditions such as Huisgen 1,3-dipolar cycloaddition between an azide and an alkyne. 


\section{Introduction}

Stromal cell-derived factor (SDF)-1/CXCL12 belongs to a family of chemoattractant cytokines known as chemokines that interact with $\mathrm{CXC}$ chemokine receptor 4 (CXCR4) on various leukocytes [1,2]. CXCR4-expressing immune cells migrate through an SDF-1 gradient, which is highly secreted from inflammatory tissues, leading to onset of the immune response under physiological conditions [3]. The SDF-1/CXCR4 axis also contributes to the migration of stem/progenitor cells to appropriate locations during embryogenesis and organogenesis, and thus knockdown of the SDF-1 or CXCR4 gene in mice causes embryonic lethality [4,5]. In addition to these physiological findings, pathological roles of CXCR4 in several diseases have been reported. CXCR4-overexpressing malignant tumor cells metastasize toward distinct organs present in a high level of SDF-1, such as the direction of breast cancer cells toward the lung, liver and bone marrow [6]. CXCR4 also plays an essential role in the entry of human immunodeficiency virus type (HIV)-1 into $\mathrm{T}$ cells $[7,8]$. Therefore, CXCR4 is a promising molecular target for anti-metastatic and anti-HIV agents, and for diagnostic agents for CXCR4-expressing malignant tumors [9-13]. Recently, CXCR7/RDC1 was identified as an alternative receptor for SDF-1 [14]. CXCR7 is also related to cancer progression and HIV infection $[15,16]$, and functions as a decoy receptor that does not trigger G-protein-dependent downstream signaling (e.g. calcium flux) upon SDF-1 interaction, unlike the case for CXCR4 $[17,18]$.

To fully appreciate the physiological and pathological roles of CXCR4 and CXCR7, tracer-conjugated receptors have been employed for visualization of the receptor localization and trafficking $[19,20]$. For example, when a fluorescent protein such as GFP was conjugated to the CXCR4 C-terminus, SDF-1-mediated CXCR4 internalization and homodimer/heterodimer formation were observed by bioluminescence resonance energy transfer and fluorescence resonance energy transfer [21-23]. In addition, an anti-CXCR4 antibody was applied to the detection of the receptors on cells [24,25]. Fluorescent CXCR4-selective antagonists including TY14003 have been also 
developed from the polyphemusin II-derived antagonist T140 [11,12] and from a bicyclam-based antagonist [26]. Conversely, there are few reports of fluorescently tagged SDF-1 derivatives, which can be used for live cell imaging after the internalization of CXCR4 and CXCR7. Herein, we report the design, synthesis and biological evaluation of fluorescent SDF-1 derivatives.

\section{Experimental section}

\section{Synthesis of Fluorescent SDF-1 Derivatives}

Protected peptide resins for the SDF-1 derivatives were synthesized by Fmoc-based solid-phase peptide synthesis on NovaSyn TGR-resin. For C-terminal Asn67 preparation, Fmoc-Asp-Ot-Bu, 1,3-diisopropylcarbodiimide and $\mathrm{HOBt} \cdot \mathrm{H}_{2} \mathrm{O}$ were agitated with NovaSyn TGR-resin for $2 \mathrm{~h}$ in DMF. For the synthesis of SDF-1(27-Pra), SDF-1(63-Pra) and SDF-1(67-Pra), Lys27, Glu63 and Asn67 were substituted with propargylglycine (Pra), respectively, using Fmoc-Pra-OH. Treatment of the resins with a trifluoroacetic acid (TFA)/1,2-ethanedithiol (EDT)/ $\mathrm{H}_{2} \mathrm{O} / m$-cresol/thioanisole (80:5:5:5:5) cocktail for $2 \mathrm{~h}$ at room temperature, followed by air oxidation, provided the expected SDF-1 derivatives containing a propargyl moiety. For the preparation of AlexaFluor ${ }^{\circledR} 488$ (AF488)or tetramethylrhodamine (TMR)-labeled peptides, the Pra-labeled peptides $(1.5 \mathrm{mM} ; 39 \mu \mathrm{L}$ in DMSO) were treated with $50 \mathrm{mM}$ AF488-azide or $50 \mathrm{mM}$ TMR-azide $(2.4 \mu \mathrm{L}$ in DMSO; Invitrogen), respectively, in the presence of $100 \mathrm{mM} \mathrm{CuSO}_{4} \cdot 5 \mathrm{H}_{2} \mathrm{O}\left(1.5 \mu \mathrm{L}\right.$ in $\left.\mathrm{H}_{2} \mathrm{O}\right)$ and $100 \mathrm{mM}$ sodium ascorbate $\left(2.95 \mu \mathrm{L}\right.$ in $\left.\mathrm{H}_{2} \mathrm{O}\right)$. The crude products were purified by preparative HPLC on a Cosmosil 5C18-AR-300 preparative column (Nacalai Tesque; $20 \times 250 \mathrm{~mm}$; flow rate, $10 \mathrm{~mL} / \mathrm{min}$ ) to afford the expected peptides. All peptides were characterized by micromass ZQ LC-MS (Waters) and the purities were calculated to be $>95 \%$ by HPLC on a Cosmosil 5C18-AR-300 analytical column (Nacalai Tesque; $4.6 \times 250 \mathrm{~mm}$; flow rate, $1 \mathrm{~mL} / \mathrm{min}$ ) at 220-nm absorbance. The HPLC profiles of the products are shown in Supplemental Figure 1. The characterizing data for the purified products are shown in Supplemental Table 1. 


\section{$\left.{ }^{125} \mathrm{I}\right]-\mathrm{SDF}-1$ binding and displacement}

To evaluate the binding affinities of the SDF-1 derivatives labeled by the green fluorophore [SDF-1(63-AF488) and SDF-1(67-AF488)], competitive inhibition assays with GF/B filters were performed using $\left[{ }^{125} \mathrm{I}\right]-\mathrm{SDF}-1$ according to a previously described procedure [13]. To evaluate the binding affinities of the SDF-1 derivatives labeled by the red fluorophore [SDF-1(27-TMR), SDF-1(63-TMR) and SDF-1(67-TMR)], CXCR4 (5.0 $\mu \mathrm{g})$ and CXCR7 (9.3 $\mu \mathrm{g})$ membranes with 0.5 $\mu \mathrm{g}$ of agglutinin-coupled SPA beads type A (GE Healthcare) were incubated with $0.5 \mathrm{nM}$ $\left.{ }^{125} \mathrm{I}\right]-\mathrm{SDF}-1$ and increasing concentrations of compounds in $100 \mu \mathrm{L}$ of binding buffer $(25 \mathrm{mM}$ HEPES pH 7.4, $50 \mu \mathrm{M} \mathrm{MgCl}_{2}, 1 \mu \mathrm{M} \mathrm{CaCl}_{2}, 140 \mathrm{mM} \mathrm{NaCl}, 250 \mathrm{mM}$ sucrose and $0.5 \% \mathrm{BSA}$ in $\mathrm{H}_{2} \mathrm{O}$ ) for $1 \mathrm{~h}$ at room temperature. The reaction mixtures were measured by a TopCount (Packard). Data were analyzed using GraphPad Prism software (GraphPad Software Inc.).

\section{Intracellular calcium mobilization}

Calcium mobilization was evaluated by aequorin assay by the Euroscreen FAST service from Euroscreen (Gosselies, Belgium). Briefly, CHO-K1 cells expressing the human recombinant CXCR4, were grown for $18 \mathrm{~h}$ prior to the test in media without antibiotics. The cells were detached by gentle flushing with PBS-EDTA (5 mM EDTA), recovered by centrifugation and resuspended in assay buffer (DMEM/F-12 with HEPES $+0.1 \%$ BSA protease free). Cells were incubated at room temperature for at least $4 \mathrm{~h}$ with coelenterazine h (Molecular Probes). $50 \mu \mathrm{l}$ of cell suspension was injected on $50 \mu \mathrm{l}$ of test compound $(200 \mathrm{nM})$ plated in a 96-well plate. The resulting emission of light was recorded using the Hamamatsu Functional Drug Screening System 6000 (FDSS 6000).

\section{Establishment of Cell Lines}


pcDNA5/FRT/TO-CXCR4 and pcDNA5/FRT/TO-CXCR7 were prepared as previously described [11]. Flp-In 293 cells or Flp-In CHO cells (Invitrogen) were maintained in Dulbecco's modified Eagle's medium (Sigma) or F-12 medium (Wako), respectively. These were supplemented with $10 \%$ heat-inactivated fetal bovine serum, $100 \mu \mathrm{g} / \mathrm{mL}$ zeocin, $100 \mathrm{U} / \mathrm{mL}$ penicillin and 100 $\mu \mathrm{g} / \mathrm{mL}$ streptomycin in $5 \% \mathrm{CO}_{2}$ at $37^{\circ} \mathrm{C}$. The $\mathrm{CXCR} 4$ mutant constructs were cotransfected with pOG44 (Invitrogen), an expression vector for Flp recombinase, into Flp-In 293 cells according to the manufacturer's protocol. The cells were cultured in the above medium in the presence of $100 \mu \mathrm{g} / \mathrm{mL}$ hygromycin. The cells showing resistance to hygromycin were selected, and the expression of CXCR4 was examined by flow cytometry as CXCR4-positive cells.

\section{Flow Cytometry Analyses}

HEK293 cells with transfection of pcDNA5/FRT/TO-CXCR4 were detached using trypsin and incubated with $5 \mathrm{nM}$ SDF-1(67-AF488) or TY14003 in $500 \mu \mathrm{L}$ of PBS containing $1 \%$ BSA at $0^{\circ} \mathrm{C}$ for $20 \mathrm{~min}$ in the presence of TF14016 [9], FC131 [10] or AMD3100 [27] as an inhibitor. After the incubation, the cells were analyzed using a FACSCalibur (BD Biosciences). Ten thousand events on probe-binding cells were analyzed per sample, and the data were collected from FL1 in the log mode. The numbers of stained cells were plotted for each competitor concentration. Data were analyzed using CellQuest Pro software (BD Biosciences).

\section{Confocal Microscopy Analyses of Ligand Internalization}

$\mathrm{CHO}$ cells (with or without transfection) were plated on $35-\mathrm{mm}$ glass-bottomed dishes and cultured in F-12 medium containing 10\% heat-inactivated fetal bovine serum supplemented with penicillin/streptomycin and hygromycin. Cells were washed once with cold F-12 medium, and incubated with fluorescent ligands [SDF-1(67-AF488) or SDF-1(67-TMR) (100 nM)] in F-12 
medium $(100 \mu \mathrm{L})$ at $37^{\circ} \mathrm{C}$ for $30 \mathrm{~min}$. After rinsing once with cold F-12 medium, cells were observed by confocal microscopy (Eclipse Ti-E: Nikon).

\section{Results and Discussion}

\section{Preparation and Biological Evaluation of the Fluorescent SDF-1 Derivatives}

SDF-1 comprises three major regions, namely an N-terminal region that plays a critical role in binding to CXCR4, a central $\beta$-sheet core structure and a C-terminal $\alpha$-helix (Figure 1a) [28]. A two-step/two-site model suggests that the N-terminal region of SDF-1 binds to the CXCR4 groove, leading to a conformational change of the receptor for G-protein binding and downstream signaling $[28,29]$. The central and C-terminal regions are involved in CXCR4 activation to induce chemotaxis [30]. To date, there have been two reports of fluorescent SDF-1 derivatives, in which the N- or C-terminus was modified. These derivatives were employed for multiparameter flow cytometry and for monitoring the CXCR4 localization [24,31]. However, comparative structure-activity relationship analyses for fluorescent SDF-1 derivatives have not been reported. Initially, we designed SDF-1 derivatives modified with several types of fluorophores at the N-terminus, Lys27 in the central region and Glu63 or Asn67 in the C-terminus.

The SDF-1 derivatives were synthesized by a standard Fmoc-based solid-phase synthesis, in which propargylglycine (Pra) was employed at the labeling sites (Lys27, Glu63 and Asn67). The resulting protected peptide resins were subjected to final deprotection and subsequent air oxidation [32]. Treatment of the alkyne-containing SDF-1 derivatives with a fluorophore-conjugated azide including AF488 or TMR in the presence of $\mathrm{CuSO}_{4}$ and sodium ascorbate provided the expected fluorescent SDF-1 derivatives (Figure 1b). For the preparation of SDF-1(N-FL), N-terminal modification of the protected peptide resin was carried out using carboxyfluorescein.

\section{Binding Affinities of the Fluorescent SDF-1 Derivatives for CXCR4 and CXCR7}


The binding affinities of the SDF-1 derivatives were evaluated as their inhibitory potencies toward $\left[{ }^{125} \mathrm{I}\right]-\mathrm{SDF}-1-$ binding to CXCR4 (Table 1). The bioactivity of SDF-1(N-FL) was significantly less potent compared with unlabeled SDF-1. Four SDF-1 derivatives with modification at the C-terminal region [SDF-1(63-AF488), SDF-1(67-AF488), SDF-1(63-TMR) and SDF-1(67-TMR)] exhibited equipotent activities to unlabeled SDF-1, regardless of the fluorophores, consistent with a previous report that these regions were irrelevant to CXCR4 binding [30,31]. Modification of the central $\beta$-sheet region with TMR [SDF-1(27-TMR)] led to a slight decrease in the binding affinity for CXCR4, while the precursor propargyl analog [SDF-1(27-Pra)] exhibited equipotent activity to unlabeled SDF-1. Although a direct interaction of the central region of SDF-1 with CXCR4 has not been reported, the iminium cation or bulky chromophore group of TMR may interfere with the possible interaction between SDF-1 and CXCR4 [33].

In addition, we investigated the binding affinities of the SDF-1 derivatives for CXCR7, which is known to be an alternative receptor for SDF-1 [14]. Similar to the case for CXCR4 binding, a significant decrease in the receptor binding of N-terminally modified SDF-1(N-FL) was observed, suggesting that the SDF-1 N-terminus is critical for the receptor binding to CXCR7 as well. Modification at the central region [SDF-1(27-TMR)] also significantly decreased the bioactivity for CXCR7. In contrast, replacement of Lys27 with Pra [SDF-1(27-Pra)] did not affect the bioactivity, although a lower number of positively charged residues in SDF-1 was reported to reduce CXCR7 binding [34]. These findings suggest that the introduction of a fluorophore functional group into the central region impairs the interaction with CXCR7. The fluorescent SDF-1 derivatives with C-terminal modification [SDF-1(63-AF488), SDF-1(67-AF488), SDF-1(63-TMR) and SDF-1(67-TMR)] reproduced the binding affinity for CXCR7. This is the first report on fluorescent probes for CXCR7, which would be applicable to further investigations of SDF-1/CXCR7 signaling. 


\section{$\mathrm{Ca}^{2+}$ Mobilization and Receptor Internalization of CXCR4-expressing Cells by Fluorescent}

\section{SDF-1 Derivatives}

CXCR4-mediated $\mathrm{Ca}^{2+}$ mobilization by the SDF-1 derivatives was evaluated using aequorin-mediated bioluminescence. SDF-1(27-TMR) showed moderate agonistic activity for CXCR4, while the fluorescent SDF-1 derivatives with C-terminal modification were almost equipotent to unlabeled SDF-1 (Figure 2). This result indicated that the fluorescent labeling at the C-terminus did not impair the agonistic activity via $\mathrm{G}$ protein-dependent signaling.

It has been reported that CXCR4 and CXCR7 are internalized by stimulation by SDF-1 [14,21]. To demonstrate translocation of fluorescent SDF-1 derivatives upon receptor binding, CXCR4-expressing CHO cells were treated with SDF-1(67-AF488) and SDF-1(67-TMR). The internalization of SDF-1 into CXCR4-expressing cells with both fluorescent SDF-1 derivatives after 30 min incubation at $37{ }^{\circ} \mathrm{C}$ were observed, whereas non-transfected $\mathrm{CHO}$ cells were not stained (Figure 3) [35]. In addition, internalization of the fluorescent SDF-1 derivatives in CXCR7-expressing CHO cells was also observed (Figure 3). Taken together, it was demonstrated that these fluorescent SDF-1 derivatives reproduced the bioactivities of intact SDF-1.

\section{Application of the Fluorescent SDF-1 Derivatives to Flow Cytometry}

The potent SDF-1(67-AF488) was applied to flow cytometry analysis of CXCR4-expressing cells. Incubation of the cells with SDF-1(67-AF488) resulted in a concentration-dependent increase in the fluorescence intensity (data not shown). When SDF-1(67-AF488) (5 nM) and the cells were incubated in the presence of a known CXCR4 antagonist, TF14016, FC131 or AMD3100, the binding of SDF-1(67-AF488) to the cells was inhibited in a concentration-dependent manner (Figure 4, Supplemental Figures 2 and 3). More potent binding inhibition was observed for TF14016 than for FC131, as previously reported $[9,10]$. Of note, the inhibitory concentrations in these assays were similar to those in the flow cytometry analyses using an antagonist-based CXCR4 probe TY14003 
[11], rather than the standard binding inhibition assays using the radioligand $\left[{ }^{125} \mathrm{I}\right]-\mathrm{SDF}-1$ (Figure 4 and Table 2).

\section{Conclusions}

We have established a preparation protocol for fluorescent SDF-1 derivatives via standard Fmoc-based solid-phase synthesis and click chemistry. The fluorescent SDF-1 derivatives with labeling at the C-terminus showed equipotent binding affinities for CXCR4 and CXCR7 to unlabeled SDF-1. Using one of the fluorescent SDF-1 derivatives, SDF-1(67-AF488), a novel binding inhibition assay for CXCR4 ligands was established by flow cytometry. Recently, Saini et al. demonstrated that FITC-ubiquitin bound to CXCR4-expressing cells and extracellular ubiquitin worked as a CXCR4 ligand [36]; however, the interaction mode of ubiquitin with CXCR4 is different from that of SDF-1 [28,37]. These fluorescent SDF-1 derivatives are more appropriate probes to evaluate the bioactivity of SDF-1/CXCR4 axis by flow cytometry, especially for inhibitory compounds of SDF-1-CXCR4 interaction. This report provides a novel and general approach to develop fluorescent chemokine derivatives with the original bioactivity.

\section{Executive summary}

- SDF-1 derivatives with an alkyne moiety can be efficiently conjugated with fluorophore-conjugated azide by click chemistry.

- N-terminal modification of SDF-1 leads to significant decreases in the binding affinities for CXCR4 and CXCR7.

- Modification at the SDF-1 C-terminal region reproduces the original bioactivity of unlabeled SDF-1 regardless of the fluorophore.

- Specific binding of a fluorescent SDF-1 derivative to CXCR4-expressing cells is observed in flow cytometry analysis. 
- A novel assay system for CXCR4 ligands by flow cytometry has been established using this fluorescent SDF-1 derivative.

- A fluorescent SDF-1 derivative has been applied to CXCR4/CXCR7 labeling and utilized as a probe in binding inhibition assays.

\section{Future perspective}

The labelled signalling molecule constitutes an important tool for biochemical studies of a receptor which is relevant to a number of disease states both in clinical use and in further clinical trials for other applications. Using the agonist-based fluorescent CXCR4 probes developed in this study, the physiological and pathological significance of CXCR4/SDF-1 signaling will be further appreciated. For the application to detect endogenous levels of CXCR4, further evaluations of these fluorescent probes are now in progress. In particular, detection of circulating tumor cells by the probes could be a promising diagnostic approach for metastatic tumors in the early stage. The fluorescent SDF-1 derivatives could also be a valuable tool for further investigations of the biological and physiological roles of SDF-1/CXCR7 signaling. 


\section{References}

1 Bleul CC, Farzan M, Choe H et al. The lymphocyte chemoattractant SDF-1 is a ligand for LESTR/fusin and blocks HIV-1 entry. Nature 382(6594), 829-33 (1996).

Viola A, Luster AD. Chemokines and their receptors: drug targets in immunity and inflammation. Annu. Rev. Pharmacol. Toxicol. 48, 171-197 (2008).

3 Kollet O, Shivtiel S, Chen YQ et al. HGF, SDF-1, and MMP-9 are involved in stress-induced human CD34+ stem cell recruitment to the liver. J. Clin. Invest. 112(2), 160-169 (2003).

Moepps B, Braun M, Knöpfle K, Dillinger K, Knöchel W, Gierschik P. Characterization of a Xenopus laevis CXC chemokine receptor 4: implications for hematopoietic cell development in the vertebrate embryo. Eur. J. Immunol. 30(10), 2924-2934 (2000).

Nagasawa T, Hirota S, Tachibana K et al. Defects of B-cell lymphopoiesis and bone-marrow myelopoiesis in mice lacking the CXC chemokine PBSF/SDF-1. Nature 382(6592), 635-638 (1996).

6* Müller A, Homey B, Soto $\mathrm{H}$ et al. Involvement of chemokine receptors in breast cancer metastasis. Nature 410(6824), 50-56 (2001). Key article demonstrating that CXCR4-expressing cancer cells metastasize toward distinct organs through the interaction of SDF-1.

7* Feng Y, Broder CC, Kennedy PE, Berger EA. HIV-1 entry cofactor: functional cDNA cloning of a seven-transmembrane, G protein-coupled receptor. Science 272 (5263), 872-877 (1996). CXCR4 acts as a co-receptor for the entry of HIV into T-cell.

8 Berson JF, Long D, Doranz BJ, Rucker J, Jirik FR, Doms RW. A seven-transmembrane domain receptor involved in fusion and entry of T-cell-tropic human immunodeficiency virus type 1 strains. J. Virol. 70(9), 6288-6295 (1996). 
anti-metastatic agents in the treatment of breast cancer. FEBS Lett. 550(1-3), 79-83 (2003).

10 Fujii N, Oishi S, Hiramatsu $\mathrm{K}$ et al. Molecular-size reduction of a potent CXCR4-chemokine antagonist using orthogonal combination of conformation- and sequence-based libraries. Angew. Chem. Int. Ed. Engl. 42(28), 3251-3253 (2003).

11* Oishi S, Masuda R, Evans B et al. Synthesis and application of fluorescein- and biotin-labeled molecular probes for the chemokine receptor CXCR4. Chembiochem 9(7), 1154-1158 (2008). Key article disclosing the development of fluorescent CXCR4 antagonists on the basis of the structure-activity relationship study of polyphemusin-II-derived antagonist T140.

12 Nishizawa K, Nishiyama H, Oishi S et al. Fluorescent imaging of high-grade bladder cancer using a specific antagonist for chemokine receptor CXCR4. Int. J. Cancer 127(5), 1180-1187 (2010).

13 Masuda R, Oishi S, Ohno $\mathrm{H}$ et al. Concise site-specific synthesis of DTPA-peptide conjugates: application to imaging probes for the chemokine receptor CXCR4. Bioorg. Med. Chem. 19(10), 3216-3220 (2011).

14** Balabanian K, Lagane B, Infantino S et al. The chemokine SDF-1/CXCL12 binds to and signals through the orphan receptor RDC1 in T lymphocytes. J. Biol. Chem. 280(42), 35760-35766 (2005). Key publication disclosing that CXCR7/RDC1 is identified as an alternative SDF-1 receptor.

15 Wang J, Shiozawa Y, Wang J et al. The role of CXCR7/RDC1 as a chemokine receptor for CXCL12/SDF-1 in prostate cancer. J. Biol. Chem. 283(7), 4283-4294 (2005).

16 Shimizu N, Soda Y, Kanbe K et al. A putative G protein-coupled receptor, RDC1, is a novel coreceptor for human and simian immunodeficiency viruses. J. Virol. 74(2), 619-626 (2000).

17 Levoye A, Balabanian K, Baleux F, Bachelerie F, Lagane B. CXCR7 heterodimerizes with 
CXCR4 and regulates CXCL12-mediated G protein signaling. Blood 113(24), 6085-6093 (2009).

18 Rajagopal S, Kim J, Ahn S et al. $\beta$-arrestin- but not G protein-mediated signaling by the "decoy" receptor CXCR7. Proc. Natl. Acad. Sci. U. S. A. 107(2), 628-632 (2010).

19 Bhandari D, Trejo J, Benovic JL, Marchese A. Arrestin-2 interacts with the ubiquitin-protein isopeptide ligase atrophin-interacting protein 4 and mediates endosomal sorting of the chemokine receptor CXCR4. J. Biol. Chem. 282(51), 36971-36979 (2007).

Luker KE, Steele JM, Mihalko LA, Ray P, Luker GD. Constitutive and chemokine-dependent internalization and recycling of CXCR7 in breast cancer cells to degrade chemokine ligands. Oncogene 29(32), 4599-4610 (2010).

21 Tarasova NI, Stauber RH, Michejda CJ. Spontaneous and ligand-induced trafficking of CXC-chemokine receptor 4. J. Biol. Chem. 273(26), 15883-15886 (1998).

22 Babcock GJ, Farzan M, Sodroski J. Ligand-independent dimerization of CXCR4, a principal HIV-1 coreceptor. J. Biol. Chem. 278(5), 3378-3385 (2003).

23 Isik N, Hereld D, Jin T. Fluorescence resonance energy transfer imaging reveals that chemokine-binding modulates heterodimers of CXCR4 and CCR5 receptors. PLoS One 3(10), e3424 (2008).

24 Dar A, Goichberg P, Shinder V et al. Chemokine receptor CXCR4-dependent internalization and resecretion of functional chemokine SDF-1 by bone marrow endothelial and stromal cells. Nat. Immunol. 6(10), 1038-1046 (2005).

25 Signoret N, Oldridge J, Pelchen-Matthews A et al. Phorbol esters and SDF-1 induce rapid endocytosis and down modulation of the chemokine receptor CXCR4. J. Cell Biol. 139(3), $651-664$ (1997).

26 Khan A, Silversides JD, Madden L, Greenman J, Archibald SJ. Fluorescent CXCR4 chemokine receptor antagonists: metal activated binding. Chem. Commun. (4), 416-418 
(2007).

27 Esté JA, Cabrera C, De Clercq E et al. Activity of different bicyclam derivatives against human immunodeficiency virus depends on their interaction with the CXCR4 chemokine receptor. Mol. Pharmacol. 55(1), 67-73 (1999).

28* Crump MP, Gong JH, Loetscher P et al. Solution structure and basis for functional activity of stromal cell-derived factor-1; dissociation of CXCR4 activation from binding and inhibition of HIV-1. EMBO J. 16(23), 6996-7007 (1997). Key article demonstrating the two-step interaction of SDF-1 with CXCR4.

29** Wu B, Chien EY, Mol CD. et al. Structures of the CXCR4 chemokine GPCR with small-molecule and cyclic peptide antagonists. Science 330(6007), 1066-1071 (2010). Key publication disclosing the crystal structure of CXCR4-ligand complex.

30 Tan Y, Du J, Cai S et al. Cloning and characterizing mutated human stromal cell-derived factor-1 (SDF-1): C-terminal alpha-helix of SDF-1alpha plays a critical role in CXCR4 activation and signaling, but not in CXCR4 binding affinity. Exp. Hematol. 34(11), 1153-1162 (2006).

31 Hatse S, Princen K, Liekens S, Vermeire K, De Clercq E, Schols D. Fluorescent CXCL12AF647 as a novel probe for nonradioactive CXCL12/CXCR4 cellular interaction studies. Cytometry A 61(2), 178-188 (2004).

32 Tamamura H, Matsumoto F, Sakano K et al. Unambiguous synthesis of stromal cell-derived factor-1 by regioselective disulfide bond formation using a DMSO-aqueous $\mathrm{HCl}$ system. Chem. Commun. (1), 151-152 (1998).

33 Dealwis C, Fernandez EJ, Thompson DA, Simon RJ, Siani MA, Lolis E. Crystal structure of chemically synthesized [N33A] stromal cell-derived factor 1alpha, a potent ligand for the HIV-1 "fusin" coreceptor. Proc. Natl. Acad. Sci. U. S. A. 95(12), 6941-6946 (1998).

34 Struyf S, Noppen S, Loos T et al. Citrullination of CXCL12 differentially reduces CXCR4 
and CXCR7 binding with loss of inflammatory and anti-HIV-1 activity via CXCR4. $J$. Immunol. 182(1), 666-674 (2009).

35 Harvey JR, Mellor P, Eldaly H, Lennard TW, Kirby JA, Ali S. Inhibition of CXCR4-mediated breast cancer metastasis: a potential role for heparinoids? Clin. Cancer Res. 13(5), 1562-1570 (2007).

36 Saini V, Marchese A, Majetschak M. CXC chemokine receptor 4 is a cell surface receptor for extracellular ubiquitin. J. Biol. Chem. 285(20), 15566-15576 (2010).

37 Saini V, Staren DM, Ziarek JJ et al. The CXC chemokine receptor 4 ligands ubiquitin and stromal cell-derived factor- $1 \alpha$ function through distinct receptor interactions. J. Biol. Chem. 286(38), 33466-33477 (2010).

\section{Acknowledgements}

This work was supported by Grants-in-Aid for Scientific Research and Targeted Proteins Research Program from the Ministry of Education, Culture, Sports, Science and Technology of Japan; and by a grant for Promotion of AIDS Research from the Ministry of Health and Welfare of Japan. R.M. is grateful for Research Fellowships from the JSPS for Young Scientists. 
Figure 1. Design and synthesis of fluorescent SDF-1 derivative. (a) Structural model of SDF-1 (PDB ID code: 1SDF). The substructures of the $\alpha$-helix (red), $\beta$-turn (green) and $\beta$-sheet (blue) are illustrated by ViewerLite software (Accelrys Inc.). (b) Representative synthetic scheme for fluorescent SDF-1 derivatives. Reagents: i) Fmoc-based SPPS; ii) TFA/ $\mathrm{H}_{2} \mathrm{O} / \mathrm{EDT} / m$-cresol/thioanisole (80:5:5:5:5), followed by air oxidation; iii) fluorophore- $\mathrm{N}_{3}$, $\mathrm{CuSO}_{4} \cdot 5 \mathrm{H}_{2} \mathrm{O}$ and sodium ascorbate.
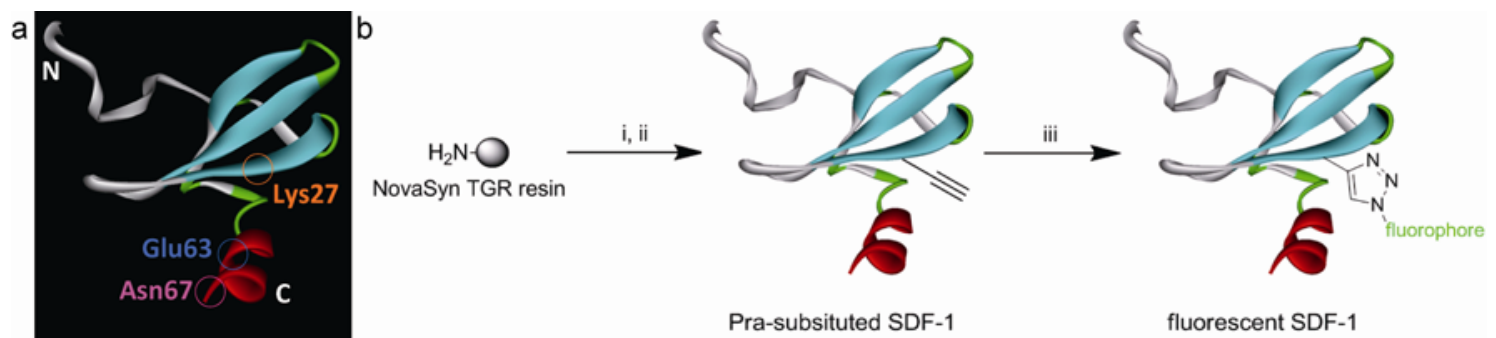
Figure 2. $\mathrm{Ca}^{2+}$ mobilization by fluorescent SDF-1 derivatives. Cells were treated with SDF-1(63-AF488) (a), SDF-1(67-AF488) (b), SDF-1(27-TMR) (c), SDF-1(63-TMR) (d) or SDF-1(67-TMR) (e). 100\% signal indicates the maximum agonistic activity by $100 \mathrm{nM} \mathrm{SDF}-1$.

a

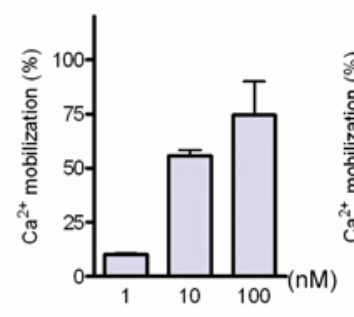

d

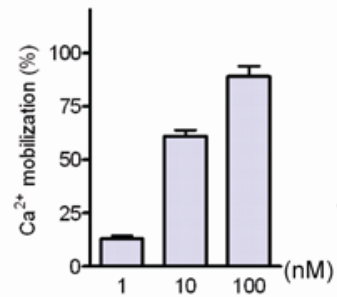

b

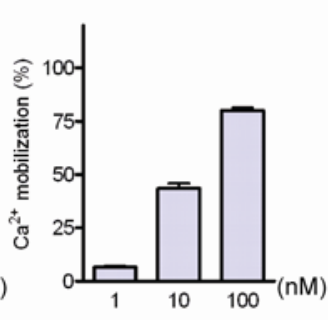

e

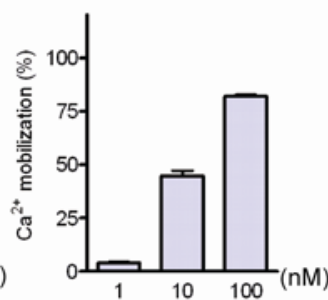

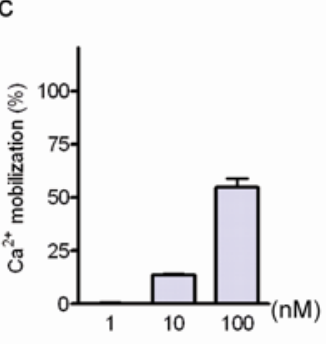


Figure 3. Confocal microscopy images of fluorescent SDF-1 derivatives: internalization into CXCR4-expressing cells (a,b), CXCR7-expressing cells (c,d) and untransfected CHO cells (e,f). Cells were treated with SDF-1(67-AF488) (a,c,e) or SDF-1(67-TMR) (b,d,f) (100 nM) for 30 min at $37^{\circ} \mathrm{C}$.

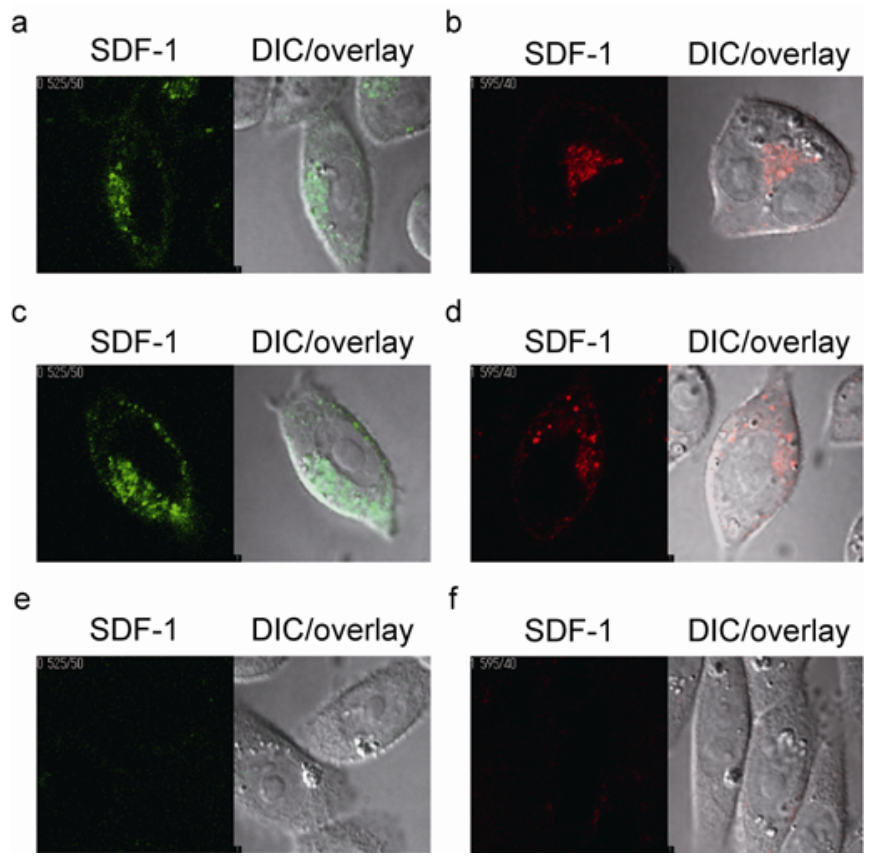


Figure 4. Flow cytometry profiles in competitive inhibition assays of the fluorescent probes against CXCR4 antagonists. CXCR4-expressing HEK cells were stained with 5 nM SDF-1(67-AF488) (a-c) or TY14003 (d-f) in the presence of TF14016 (a,d), FC131 (b,e) or AMD3100 (c,f) at $0^{\circ} \mathrm{C}$ for $20 \mathrm{~min}$. $100 \%$ indicates the probe binding in the absence of the antagonist.
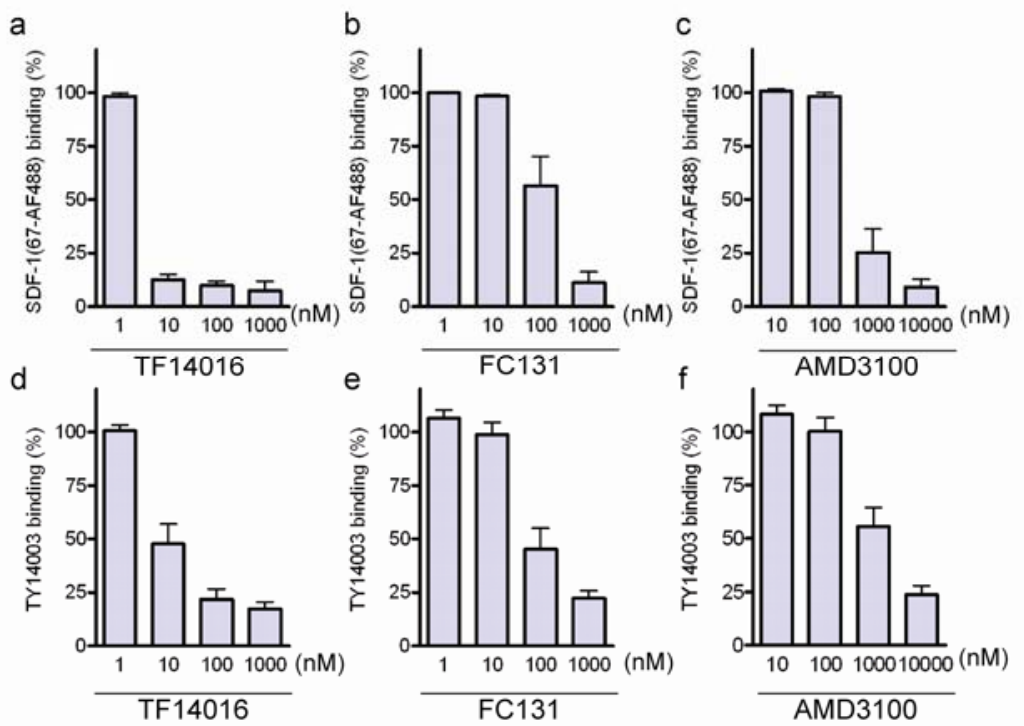
Table 1. Binding activities of the fluorescent SDF-1 derivatives.

\begin{tabular}{|c|c|c|c|c|}
\hline \multirow[t]{2}{*}{ peptide } & \multirow{2}{*}{$\begin{array}{l}\text { substituted } \\
\text { amino acid }\end{array}$} & \multirow[t]{2}{*}{ fluorophore } & \multicolumn{2}{|c|}{$\mathrm{IC}_{50}(\mathrm{nM})^{a}$} \\
\hline & & & CXCR4 & CXCR7 \\
\hline SDF-1 & - & - & $2.3^{c}, 4.3^{d}$ & $6.6^{c}, 11^{d}$ \\
\hline SDF-1(N-FL) $)^{b}$ & - & fluorescein & $580^{c}$ & $730^{c}$ \\
\hline SDF-1(27-Pra) & Lys27 & - & $2.4^{c}$ & $5.2^{c}$ \\
\hline SDF-1(63-Pra) & Glu63 & - & $3.3^{c}$ & $1.4^{c}$ \\
\hline SDF-1(67-Pra) & Asn67 & - & $2.7^{c}$ & $2.8^{c}$ \\
\hline SDF-1(63-AF488) & Glu63 & AlexaFluor $^{\circledR} 488$ & $2.9^{c}$ & $11^{c}$ \\
\hline SDF-1(67-AF488) & Asn67 & AlexaFluor $^{\circledR} 488$ & $5.6^{c}$ & $14^{c}$ \\
\hline SDF-1(27-TMR) & Lys27 & tetramethylrhodamine & $97^{d}$ & $490^{d}$ \\
\hline SDF-1(63-TMR) & Glu63 & tetramethylrhodamine & $7.6^{d}$ & $17^{d}$ \\
\hline SDF-1(67-TMR) & Asn67 & tetramethylrhodamine & $12^{d}$ & $29^{d}$ \\
\hline
\end{tabular}

${ }^{a}$ The $\mathrm{IC}_{50}$ values are the concentrations required for $50 \%$ inhibition of the $\left[{ }^{125} \mathrm{I}\right]-\mathrm{SDF}-1$ binding to CXCR4 and CXCR7. ${ }^{b}$ Fluorescein was conjugated at the Lys1 $\alpha$-amino group. ${ }^{c}$ Data from filter plate ligand assays. ${ }^{d}$ Data from SPA binding assays. 
Table 2. Data from binding inhibition assays of CXCR4 antagonists using fluorescent probes or the radioligand.

\begin{tabular}{|c|c|c|c|c|}
\hline \multirow[b]{2}{*}{ antagonist } & \multicolumn{4}{|l|}{$\mathrm{IC}_{50}(\mathrm{nM})^{a}$} \\
\hline & $\begin{array}{l}\text { SDF-1(67-AF488) } \\
\text { binding inhibition }\end{array}$ & $\begin{array}{l}\text { TY14003 } \\
\text { inhibition }^{b}\end{array}$ & binding & $\begin{array}{l}{\left[{ }^{125} \mathrm{I}\right]-\mathrm{SDF}-1 \text { binding }} \\
\text { inhibition }^{c}\end{array}$ \\
\hline TF14016 & 2.44 & 4.68 & & 3.98 \\
\hline FC131 & 108 & 52.7 & & 280 \\
\hline AMD3100 & 444 & 794 & & 798 \\
\hline
\end{tabular}

${ }^{a}$ The IC 50 values were derived from dose-response curves generated from triplicate data points. ${ }^{b}$ Data from flow cytometry analyses. ${ }^{c}$ Data from SPA binding assays. 